\title{
Mark W. Bondi, PhD, Recipient of 2016 Alzheimer Award
}

The Journal of Alzheimer's Disease (JAD) is pleased to announce that Mark W. Bondi, PhD, ABPP/CN, Prtofessor of Psychiatry at UC San Diego and Director of the Neuropsychological Assessment Unit at the VA San Diego Healthcare System, has been chosen as the recipient of the 2016 Alzheimer Award presented by the journal in recognition of his outstanding work on the development of a novel and promising method of staging preclinical Alzheimer's disease (AD) based on number of abnormal biomarkers that is predictive of progression to mild cognitive impairment (MCI) and AD.

The winning paper is "Subtle Cognitive Decline and Biomarker Staging in Preclinical Alzheimer's Disease" [1].

This yearly award is made possible by support from the Alzheimer's Research \& Prevention Foundation (http://www.alzheimersprevention.org/) and IOS Press.

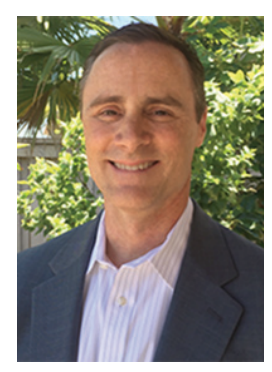

Dr. Mark W. Bondi received his $\mathrm{PhD}$ in clinical psychology and neuropsychology from the University of Arizona in 1991. He completed his internship and fellowship training at UC San Diego and joined the faculty in 1994. He is currently Professor of Psychiatry at UC San Diego and Director of the Neuropsychological Assessment Unit at the VA San Diego Healthcare System. He has served on several elected boards of the American Psychological Association, the Board of Directors of the American Board of Clinical Neuropsychology, and Board of Governors of the International Neuropsychological Society. He is a Fellow of the American Psychological Association and National Academy of Neuropsychology, and he is President-Elect of the Society for Clinical Neuropsychology (Division 40 of APA). Since 1991 he has received continuous funding from NIH, VA, and private foundation grants; he is the recipient of a Mid-Career Investigator Award in Patient-Oriented Research from NIA; and he is sponsor or co-sponsor of $11 \mathrm{NIH}$ and VA career development awards of his current and former trainees. His research centers on the cognitive and brain changes of individuals at risk for dementia, and he has published more than 165 articles, books, and chapters.

\section{Importance of Published Article}

The NIA-AA criteria for "preclinical” Alzheimer's disease [2] propose a staging method in which AD biomarkers follow an invariant temporal sequence in accordance with the amyloid cascade model: Stage 1 refers to amyloid accumulation only; Stage 2 refers to amyloidosis plus neurodegeneration; and Stage 3 requires both plus evidence of subtle cognitive decline. However, our study findings [1] did not conform to this sequence. We found that, among participants in the Alzheimer's Disease Neuroimag- 
ing Initiative, neurodegeneration alone was 2.5 times more common than amyloidosis alone at baseline. For participants who demonstrated only one abnormal biomarker at baseline and later progressed, neurodegeneration was most common. Amyloidosis only or subtle cognitive decline only were less common — and equally common. Thus, the majority did not show amyloid positivity as the first sign of their eventual progression to MCI or AD diagnosis, suggesting that most individuals do not follow the temporal order proposed by NIA-AA criteria. In this article we also provide an operational definition of subtle cognitive decline that follows from our prior work on defining MCI via actuarial neuropsychological criteria [3], and we offer a new approach to staging preclinical AD based on number of abnormal markers without regard to their temporal order. This method of characterizing preclinical AD is more parsimonious than the NIA-AA staging system and does not presume that all patients follow a singular invariant expression of the disease in accordance with the amyloid cascade model.

\section{REFERENCES}

[1] Edmonds EC, Delano-Wood L, Galasko DR, Salmon DP, Bondi MW (2015) Subtle cognitive decline and biomarker staging in preclinical Alzheimer's disease. J Alzheimers Dis 47, 231-242.

[2] Sperling RA, Aisen PS, Beckett LA, Bennett DA, Craft S, Fagan AM, Iwatsubo T, Jack CR Jr, Kaye J, Montine TJ, Park DC, Reiman EM, Rowe CC, Siemers E, Stern Y, Yaffe K, Carrillo MC, Thies B, Morrison-Bogorad M, Wagster MV, Phelps CH (2011) Toward defining the preclinical stages of Alzheimer's disease: recommendations from the National Institute on Aging-Alzheimer's Association workgroups on diagnostic guidelines for Alzheimer's disease. Alzheimers Dement 7, 280-292.

[3] Bondi MW, Edmonds EC, Jak AJ, Clark LR, Delano-Wood L, McDonald CR, Nation DA, Libon DJ, Au R, Galasko D, Salmon DP (2014) Neuropsychological criteria for mild cognitive impairment improves diagnostic precision, biomarker associations, and progression rates. JAlzheimers Dis 42, 275289. 